\title{
Learning from the Past: Reflecting on the Maya-ICBG Controversy in the Classroom
}

\author{
Daniela Shebitz $^{1^{*}}$ and Angela Oviedo ${ }^{1}$ \\ ${ }^{1}$ School of Environmental and Sustainability Sciences, Kean University, Union, NJ, USA. \\ *dshebitz@kean.edu
}

\begin{abstract}
In the 1990s, the Maya-ICBG (International Cooperative Biodiversity Group) was one of the major bioprospecting projects in Chiapas, Mexico and was designed to incorporate traditional knowledge into pharmaceutical research. The researchers had hopes of benefiting Indigenous communities economically and technologically while conserving plants and traditional knowledge. Unfortunately, the project experienced local and international opposition who accused the project of exploiting Indigenous people and privatizing their knowledge. We present a teaching module in the form of an interrupted case study in which participants learn about the ethnobotanical study that shifted from one of promise to one of controversy. The history of the development of the case study over the past decade is told from both a faculty and a student perspective. The purpose of this perspective article and of our case study in general is to bring the conversation of ethics to the forefront of ethnobiology. Although the Maya-ICBG project was brought to a close in 2001, the case study is still relevant in both a historical context and as a means to discuss ethics and Prior Informed Consent.
\end{abstract}

Received August 30, 2017

OPEN ठACCESS

Accepted January 6, 2018

DOI 10.14237/ebl.9.1.2018.1095

Keywords Case study, Maya-ICBG, Prior Informed Consent, Bioprospecting, Chiapas, Mexico

Copyright (c) 2018 by the author(s); licensee Society of Ethnobiology. This is an open-access article distributed under the terms of the Creative Commons Attribution-NonCommercial 4.0 International Public License (https://creativecommons.org/licenses/by-nc/4.0), which permits non-commercial use, distribution, and reproduction in any medium, provided the original author and source are credited.

Faculty Perspective, Daniela Shebitz

In the late 1990s, the Maya-ICBG (International Cooperative Biodiversity Group) was one of the major bioprospecting projects in Chiapas, Mexico and was designed to incorporate traditional knowledge into pharmaceutical research. The researchers hoped to benefit Indigenous communities economically and technologically while conserving plants and traditional knowledge. The primary investigator of the MayaICBG Project was University of Georgia professor of Anthropology Dr. Brent Berlin, who was one of the founders and past presidents of the International Society of Ethnobiology (ISE).

I had just started my second year of my Master's Degree program in the fall of 2000 when I traveled to Georgia for the first United States-based conference of the ISE. Dr. Berlin was the main organizer of the event, and I had come to recognize him as a leader in the field of ethnobiology based on his decades of remarkable work with the Maya. The ISE conference was intended to bring together scientists and Indigenous people from throughout the world to discuss "Ethnobiology, Biocultural Diversity and Benefits Sharing". Berlin stated that: "We intend to face head-on several difficult issues relating to benefits sharing resulting from biodiversity research. We believe there will be an important sharing of ideas during this week." (AAAS 2000).

While a discussion of biocultural diversity and benefits sharing did take place, unfortunately the ISE conference revealed to the ethnobiological community that there was much local and international opposition to the Maya-ICBG project. Many of the conference participants were actually protesting the work that Dr. Berlin and his colleagues were conducting in Chiapas by accusing the ethnobiologists of exploiting Indigenous people and privatizing their knowledge. They claimed that commercially using medicinal plants conflicted with the collective traditions and religions of the Maya. As a young ethnobiologist at the time, the confrontation that occurred at the conference and was directed at a leader in the field of ethnobotany was both troubling and influential. At that point in my life, I had a romanticized view of the work that ethnobiologists do 
and had not truly considered the complexities of working with Indigenous people.

Throughout the conference, there were meetings between the various stakeholders that were open to all conference participants. I did not know any other attendees personally at the time, but in the 17 years that have elapsed, I have come to learn that many of my current colleagues, mentors, and friends were also present in those meetings, either as part of a panel or in the audience. It turns out that most of the attendees who I have come to know well were also influenced by the confrontations that occurred at the conference and have carried lessons that they learned through the meetings with them.

I have since become a professor who teaches about and conducts research in the field of ethnobiology. While I have never had the opportunity to work in Mexico, lessons I have taken from the Maya-ICBG program have become woven through my research. In particular, I have come to realize that there are countless perspectives on a given project. There are often many factors that are beyond an individual's control as a researcher to consider when designing and implementing a project that can make a seemingly simple project become complex. Importantly, while guidance and tools are available to ethnobiologists, it is essential to recognize that there is not one correct way to conduct a study. Each situation is different based on place, political climate, environment, local, regional economy, and of course the people involved.

Over the past decade, I have been teaching an undergraduate upper-division course entitled "Medicinal Botany" at Kean University in New Jersey as part of the Environmental Biology program. Most students in that class have not had an anthropology course, nor have they had the opportunity to conduct research with people. While I had first incorporated the Maya-ICBG project as part of a lecture, I quickly realized that this material is better presented as an interactive case study. Case studies allow instructors to not just transfer knowledge to students, but to help them build their own knowledge in a contextual, social and interactive manner (Nath 2005). The first method used was to divide the students into groups involved with the fate of the Maya-ICBG project, and each had to argue their perspective based on assigned readings. Presentations were followed by a discussion about the strengths of each stakeholders' points. After learning about different case study techniques, one of the students in the class (the co-author on this paper), was inspired to turn the Maya-ICBG controversy into a format that could be adapted for use in other classes. We wrote up the project as an interrupted case study, through which information is presented piecemeal to students to mimic the way that scientists actually analyze problems (Herreid 2005). As with Problem-Based Learning (PBL), the interrupted case method involves incrementally revealing information to students working in groups and engages all students in problem solving. The difference from PBL is that the interrupted method can be presented in one long class period rather than over a greater number of days (Herreid 2005).

My student and I developed the case study based on publicly available information as we did not have any background information from the researchers, Indigenous people, or other stakeholders involved. We fully acknowledge that there is a wealth of information and perspectives that is not available through publications and websites, but we limited our case to publicly available information in order to present an abridged version of this complex project. While this approach may be perceived as being too simplistic by those individuals who were involved, we are bringing the case study forward as a means to initiate a conversation which we hope will be held in classrooms across the world. In this paper, we will present a summary of the case study to provide background information while emphasizing that we do so with great respect for both the researchers and the Indigenous people involved with the Maya-ICBG project. We acknowledge that there are great risks associated with taking an extraordinarily complex event in history and summarizing it not only for the original case study, but even more so here. However, we present it simply so that readers can understand the basis of this project and the controversy around it as a teaching tool and a means to start a much longer conversation about ethics.

\section{Student Perspective, Angela Oviedo}

I first heard about the Maya-ICBG incident in the "Medicinal Botany" course previously described as being an undergraduate course at Kean University. Like many of my classmates, I had not heard of the incident prior to the assignment. While the memory seemed to be fresh in Dr. Shebitz's mind, my peers and I were toddlers at the time of the conference. At first, therefore, it seemed unusual to learn about a historic study that failed, rather than succeeded. The 
case study platform at the time was one of roleplaying in which each "team" of students represented either the researchers, the Maya communities, the opposing parties (COMPITCH and RAFI, described below), or the partners in the ICBG project (ECOSUR and the pharmaceutical company). Once the class presented their perspectives, we began to see how multifaceted the event was, and how difficult it would have been for this project to succeed. After the course, I became interested in scientific integrity and wanted to explore the history of the Maya-ICBG project further. I worked with my mentor to develop a different way for presenting this case, in a format that would unfold before the student's eyes. In this manner, they could truly begin to understand how even though there was great promise and hope at the beginning of the project, there were many elements at play that led to its premature ending. I quickly came to understand that to many students this would provide an important lesson in understanding how even well-developed studies can end abruptly, and how important it is to consider the many players involved in a project.

After a draft of the interrupted case study was written, we presented it to the Medicinal Botany course that met the year after mine. Through the feedback of my peers, we continued to modify the case to incorporate their suggestions for improvement. The process of receiving critical evaluations of the case that I had worked diligently on for a year was important for my professional development and was incredibly rewarding. My growth continued when we submitted it for publication through a national database so that it could be publicly available (see below).

Starting a discussion about ethics by using past real-life events is not only appropriate but provides a great history lesson to those aspiring to enter the field of ethnobiology. Prior to completing our work, I had not heard of bioprospecting or the ICBG (International Cooperative Biodiversity Groups). I now have not only learned of the incident itself and about the people directly involved, but I also learned of the social and political elements that come into play while working with Indigenous communities. I hope that with this teaching case study the students not only learn about the ethical procedures involved, but also about the people and organizations involved and come to understand the importance of having an ongoing open discussion about ethics in the field.

\section{Summary of the Case Study}

The case study takes part in five stages, from the project's inception to its untimely conclusion. The case is available in its entirety through the National Center for Case Study Teaching in Science (Oviedo and Shebitz 2018) and is appropriate for undergraduates in various majors pertaining to ethnobiology. The main goal is to teach about the complexities associated with bioprospecting and reasons for an ethnobotanical project's success or failure. In addition to the five stages, the complete case study includes teacher's notes, discussion questions for each of the stages with possible answers, and a list of references for further information.

Below we summarize the case study as a teaching tool, but we emphasize that we are simplifying an already condensed version of the controversy surrounding the Maya-ICBG project. We present the summary here so that readers may be introduced to the material and to invite them to learn more about it through either our complete case study or through their own research and experiences.

The instructors are first asked to define key terms and provide background information before introducing the case study. The case can be completed during two or three consecutive classes, with each period having one or two stages based on the length of discussion. There are five major sections, with discussion questions provided for each section. For each stage, there are three separate time slots: 1) an independent evaluation, 2) small group discussions, and 3) an open classroom discussion. Below we summarize each of the five stages so that you may further understand the background information and the structure of the classroom tool.

\section{Stage One}

The students learn that the ICBG program was established by the National Institute of Health (NIH), National Science Foundation (NSF), and United States Agency for International Development (USAID) to stimulate the field of bioprospecting and provide models for the sustainable use of biodiversity (Berlin and Berlin 2004; Nigh 2002; Rosenthal 1997). Drs. Brent Berlin and Elois Ann Berlin, both anthropology professors from the University of Georgia, first applied for ICBG funding in 1992 based on work they began in 1987 (Berlin et al. 1999). This original proposal was rejected primarily because there was not a private industrial partner that was well suited to handle the large-scale pharmaceutical analysis 
that the team proposed (Berlin et al. 1999; Berlin and Berlin 2004; Nigh 2002). When the Berlins applied again in 1997, they intended to continue research that they had been conducting in the five years that elapsed since the first proposal (Berlin et al. 1999). This time, the Maya-ICBG was awarded a five-year grant involving the following partners: 1) The University of Georgia, 2) El Colegio de la Frontera Sur (ECOSUR), the host institution in Chiapas with local researchers in fields ranging from botany to economics and rural development, and 3) Molecular Nature Limited (MNL), a pharmaceutical firm with expertise in plant natural products chemistry, biochemistry, botany, and business. The major goals of the Maya-ICBG were to discover, isolate, and evaluate agents from medicinal plants with a significant potential to aid human health and the financial status of the Maya people. They also planned to initiate surveys of the plants in the Chiapas Highlands by municipality and enhance and support research training by developing a modern natural products laboratory to advance drug discovery and strengthening academic exchange between the University of Georgia and Mexico (Berlin et al. 1999).

\section{Stage Two}

Students are given background information on the Berlins' previous research, the goals of the Maya ICBG project for the collaborating communities, and the social organization the Highland communities of Chiapas. The sociodemographics of the communities greatly contribute to the complexity of this study. Approximately 8,000 villages and 900,000 Maya individuals are present in the Highlands of Chiapas, most of whom live in poverty and are divided by religious and political conflict. Importantly, they lack local authorities that are allowed to speak on behalf of all community members, making it exceptionally challenging to gain Prior Informed Consent (PIC) to conduct the study with each community (Bjorkan and Qvenild 2010; Rosenthal 2006). Berlin and Berlin (2004) argued that the project went through an extensive process of obtaining PIC from the communities based on the Convention on Biological Diversity (CBD) guidelines for ethical bioprospecting research. In order to receive PIC, The Maya-ICBG developed a theatrical performance to explain the project to the community leaders in their native languages (Berlin and Berlin 2004a). The skits included information about the purpose of the project, the manner in which information would be collected, and laboratory procedures that would be used on the biological material gathered (Berlin and Berlin 2004). Leaders from 47 communities, along with the Council of Traditional Indigenous Doctors and Midwives from Chiapas (COMPITCH), were invited to see the presentation and tour the laboratories and gardens located at ECOSUR (Berlin and Berlin 2004; Nigh 2002; Soto 2000). Attendees were then provided with summaries of the project's goals and proposed benefit sharing program, both in Spanish and their Indigenous language (Berlin and Berlin 2004).

Attendees returned to their communities and discussed in assemblies the possibility of participating in the project. The Maya-ICBG performed the skits at each community that expressed interest (Bjorkan and Qvenild 2010). Elections were held and 46 out of 47 communities agreed to participate. Participants were then asked to sign formal agreements, although the individuals who signed varied by community since the ICBGs request for proposals stated that all projects were to respect local customs (Berlin and Berlin 2004; Rosenthal 1997). Those who signed consent forms ranged from heads of households to elected community leaders (Berlin and Berlin 2004). After consent was granted, the Maya-ICBG planned to establish a nonprofit association Protection of Maya Intellectual Property Rights (PROMAYA). PROMAYA was to consist of individuals selected by participating communities to distribute any future revenue to develop community herbal gardens, scholarships, and other activities to improve social and cultural well-being (Berlin and Berlin 2004a). Although actions taken by the Maya-ICBG in terms of PIC were intended to maintain harmony among participating parties, several organizations began to question their activities.

\section{Stage Three}

This is the stage in which the opposition reacts to the project and students begin to understand the complexities associated with PIC. COMPITCH argued that there was a lack of regulations designed for bioprospecting in Mexico. Their perspective was that the project should not continue until such regulations were formulated (Nigh 2002). COMPITCH formed a partnership with a Canadian NGO, the Rural Advancement Foundation International (RAFI) to run a campaign against the Maya-ICBG (Berlin and Berlin 2004; Nigh 2002; Rosenthal 2006). Perhaps the greatest disagreement in terms of this 
study is over how PIC was attained. RAFI and COMPITCH argued that the PIC obtained by the Maya-ICBG did not adequately represent participant communities and involved a lack of respect for local historical processes for decision-making (Bjorkan and Qvenild 2010). In reference to the term "prior", the opposition claimed that biological samples resources were obtained before authorizing signatures were acquired since the Berlins had been conducting research in the area for decades before the project started (Hardison 2000). When the aspect of "informed" is examined, the opposition claimed that there was a bias when presenting the project's activities to the local communities. They state that the Maya-ICBG failed to inform the community through official assemblies and instead informed individual families through theatrical performances. They argued that there was also a failure to disclose all possible local and global impacts the project might have (Hardison 2000). Finally, in terms of "consent," the opposition challenged the Maya-ICBG's claim to having achieved written consent from all participating members as a result of the locals not having been adequately informed (Hardison 2000). The opposition declared that participating communities did not have the power to give consent over biological and intellectual resources that were shared among many communities. They argued that all Chiapas communities should have been approached (Berlin and Berlin 2004; Hardison 2000). While it was clear that efforts of obtaining PIC were made, through this stage of the case study, the students read about how difficult it is to determine exactly who can grant the consent when there are hundreds of communities in the region that are either directly or indirectly influenced by the research.

\section{Stage Four}

Students now see that despite the efforts of the MayaICBG to convince the opposition of the great benefits that the Indigenous people would gain from the project, their work was forced to a standstill when the Maya-ICBG was asked by the Governor of Chiapas to redesign their project's methods (Action Group on Erosion 2001; Berlin and Berlin 2004). For the remaining three years of the grant, the NIH allowed the project to focus on developing new procedures for obtaining PIC. The new plan included workshops led by Mexico's prominent biodiversity experts that would familiarize the Maya with environmental policy (Berlin and Berlin 2004). This new proposal was presented to the opposition, but was rejected immediately (Action Group on Erosion, 2001; Berlin and Berlin 2004; Nigh 2002). By then, the opposition had gained more followers, including Mexican intellectuals and international NGOs (Berlin and Berlin 2004). Due to the negative publicity, the host institution ECOSUR withdrew from the project and the project therefore ended in October of 2001 (Action Group on Erosion 2001; Anderson et al. 2002; Nigh 2002; Berlin and Berlin 2004).

The opposition portrayed the Maya-ICBG project as an example of how the United States was trying to exploit Mexico, how scientists would steal traditional knowledge, and how Indigenous rights were being usurped (Berlin and Berlin 2004). The Maya-ICBG scientists, however, argued that the opposite was true and that the NGOs who opposed their project took local community autonomy away from the Indigenous communities that agreed to participate even though they had no legitimate authority to speak for them (Berlin and Berlin 2004). As Bjorkan and Qvenild (2010) stated, the scientists involved associated with the Maya-ICBG and the NGO opposition both claimed to have the best interests of the Indigenous communities in mind. While the Maya-ICBG wanted to bring development and knowledge preservation to the Indigenous communities, COMPITCH and RAFI wanted to protect the Indigenous culture and knowledge, and to protect the biological resources from "biopiracy and the greedy scientists" (Bjorkan and Qvenild 2010:198).

Stage Five

Through this final stage, students see that resolving legal and ethical dilemmas such as that of PIC may prove to be problematic since no single standard or law will easily suit all international ventures. In addition, many countries such as Mexico do not have laws established to protect the traditional knowledge of Indigenous communities (Andrzejewski 2010; Garcia 2007).

\section{Reflections}

As ethnobiologists, our desire to work with and learn from other communities is often met with scrutiny, fear, and trepidation. These concerns are all too often well-founded and based on prior instances where knowledge held by community members was taken from them and their rights violated by outsiders. Projects may be rejected by the Indigenous communities even though ethnobiologists feel as 
though they are taking great precautions to protect the people they are trying to work with, as was the case with the Maya-ICBG Project. Many of those who are familiar with the Berlin's perspective argue that the Maya ICBG program was fraught with opposition before it even started that would have made it difficult, if not impossible, to succeed. Their position is that the project was not developed with any malicious intent or lack of ethics. To the contrary, the researchers had a clear desire to empower the Indigenous people, not to exploit them as the opposition argued.

It is understandably frustrating to analyze the Maya-ICBG controversy in hindsight and still not know what could have been done differently to ensure that the project would succeed. After the Berlins' first ICBG proposal was rejected for not including a partnership with the private pharmaceutical corporation, they included MNL to handle largescale analysis of samples. It is important to note, however, that the opposition argued against knowledge obtained from individual Maya being patented by researchers or by foreign pharmaceutical companies, such as MNL. Furthermore, there was great concern that the collective knowledge of the Maya communities in Chiapas was being privatized without the PIC of individuals. By establishing PROMAYA, the Berlins hoped to manage benefit sharing with the Maya communities and obtaining PIC (Berlin and Berlin 2004; Soto 2000).

The many layers of complexity make it impossible to know at this point whether anything could have been done differently to yield a successful project. That said, there are a number of essential lessons from the case study that can transcend the classroom and influence our understanding of what makes an ethnobiological research project complex. First, in terms of PIC, is that there is a lack of uniformity and government structure between Indigenous communities. The method of consent mapping onthe-ground is very different from the idealistic notion of consent that can be written and read about. In this particular example, researchers believed that they were using the most culturally appropriate method of obtaining consent through the theatrical performances for community representatives first, and then for the communities that expressed interest. However, the Indigenous communities found fault with their PIC techniques. In general, PIC is formulated differently for each institution and community. It is therefore misguided to assume that one can impose a method used by a community for acquiring PIC onto another community. Also, timing is incredibly pivotal for the ultimate success or failure of a project since no research happens in a historical vacuum. During the late 1990s when this project was occurring, much was changing not only in Central America, but also globally in terms of international research permits, border policies, and international efforts to protect biodiversity. At the same time, this Maya-ICBG project was specific to Mexico and to that particular time in history, during which there was political unrest in the region. Therefore, had it been conducted elsewhere or at any other time, it is likely that there would have been different results. There are levels of influence ranging from the very local to the global that can influence the outcome of each individual project.

The untimely end to this project was partially due to disagreement about whether communities that use the same biological resources must all consent before bioprospecting can take place. Biological resources and Indigenous knowledge of those resources often do not fall neatly within geographic or political borders or community boundaries. While many issues remain, there has been significant evolution in biodiversity law and policy at community, national, and international levels around the world since the Maya-ICBG project.

One notable and relevant shift involves the completion in 2006 of the ISE Code of Ethics, which was in an early draft form and still under development at the time the ICBG-Maya was active. Specific to the topic of consent, the draft Code of Ethics included the "Principle of Prior Informed Consent and Veto" that recognized "prior informed consent of all peoples and their communities must be obtained before any research is undertaken." It went on to say: "Providing prior informed consent presumes that all potentially affected communities will be provided complete information regarding the purpose and nature of the research activities and the probable results" (personal communication with ISE Ethics Program co-chair, Kelly Bannister, based on archived ISE documents; italics added for emphasis).

In the ensuing years, the ISE Code of Ethics underwent significant changes based on extensive input from its members (International Society of Ethnobiology nd). In the final version, which was unanimously adopted by membership vote in 2006, the specific guidance on consent was changed to the 
"Principle of Educated Prior Informed Consent" and referred to "all directly affected communities." It also included recognition that "prior informed consent requires an educative process that employs bilingual and intercultural education methods and tools, as appropriate, to ensure understanding by all parties involved" (ISE CoE 2006 with 2008 additions; italics added for emphasis). Input on the draft Code of Ethics was received from ISE members, including the Berlins, and discussed at a special ethics session held at the 2004 ISE Congress in Canterbury, UK (Bannister et al. 2004). Through the willingness of the Berlins to share their challenges with the ethnobiology community, lessons from the Maya-ICBG contributed positively to changes in the ISE Code of Ethics (personal communication with ISE Ethics Program co-chair, Kelly Bannister).

The revisions to the ISE Code of Ethics can be interpreted as supportive of the Berlins' view that it is unrealistic to expect that consent should be obtained from all communities where the same biological resources might potentially be found (Berlin and Berlin 2004). The ISE Code of Ethics promotes consent as "an ongoing process that is based on relationship and maintained throughout all phases of research." This shift in the ISE Code of Ethics represents lessons that the organization learned from the Maya ICBG controversy and likely presents a possible solution to the kind of situation presented in the case study.

Over the past decade, there have been additional efforts to protect not only the rights of Indigenous people, but also of the culturally important resources upon which they depend. The 1992 CBD recognized sovereign control over biological resources by Nation States. The Nagoya Protocol was adopted in 2010 as a supplementary agreement to the CBD to provide a transparent legal framework for the implementation of fair and equitable sharing of benefits out of the utilization of genetic resources. It also covers TEK associated with genetic resources such as plants and the benefits that arise from their use (Convention on Biological Diversity 2018). After the adoption of the Nagoya Protocol, a stringent research protocol was established by Mexico's Secretariat of Environment and Natural Resources (SEMARNAT) that requires detailed permits for the collection of biological samples and specimens to be granted by the Mexican government.
The purpose of this perspective article and of our case study in general is to bring the conversation of ethics to the forefront of ethnobiology. Although the Maya-ICBG project was brought to a close in 2001, the case study is still relevant in both a historical context and as a means to discuss ethics and PIC. We argue that it is essential to not only report on instances where projects went as hoped and both the researchers and the local communities benefited, but it is equally important to learn from situations in which projects were not carried out successfully. Exploring past studies and asking questions about their relevance today is especially useful for students looking to one day conduct their own field work. This case study is not intended to discourage them from pursuing their interest in ethnobiology, but to show the importance of understanding the perspectives of the multiple stakeholders that often exist within a region.

\section{Acknowledgements}

We acknowledge Dr. Brent Berlin for reviewing the original case study for the National Center for Case Study Teaching in Science, and are grateful to Dr. Kelly Bannister and Dr. Liz Olson for sharing their knowledge, experience and insight with us.

\section{Declarations}

Permissions: None declared.

Sources of funding: None declared.

Conflicts of Interest: None declared.

\section{References Cited}

AAAS (American Association for the Advancement of Science). 2000. University of Georgia to host $7^{\text {th }}$ International Congress of Ethnobiology in October. Available at: https:// www.eurekalert.org/pub_releases/2000-10/AAftUoGt-0510100.php. Accessed on June 26, 2017.

Action Group on Erosion, Technology and Conservation. 2001. Proyecto de biopiratería en México cancelado definitivamente [web page]. Available at: http://www.etcgroup.org/es/ content/proyecto-de-biopirater $\% \mathrm{C} 3 \%$ Ada-en-m $\%$ C3\%A9xico-cancelado-definitivamente. Accessed on June 26, 2017.

Anderson, E., B. Berlin, Berlin, E. A., and J. R. Stepp. 2002. On Maya Medicine and the Biomedical Gaze. Current Anthropology 43:789-793. 
Andrzejewski, A. 2010. Traditional Knowledge and

Patent Protection: Conflicting Views on

International Patent Standards. Potchefstroom Electronic Law Journal/Potchefstroomse Elektroniese Regsblad (PER/PELJ) 13:94-125.

Bannister, K., M. Solomon, G. Dutfield, J. Velásquez Runk, and W. McClatchey. 2004. Addressing Ethical and Legal Issues in Ethnobiology: A Deliberative Dialogue on the ISE Draft Guidelines for Research. Panel presentation at the 9th International Congress of Ethnobiology University of Kent, Canterbury, United Kingdom.

Berlin, B., and E. A. Berlin. 2004. Community Autonomy and the Maya-ICBG Project in Chiapas, Mexico: How a Bioprospecting Project that Should Have Succeeded Failed. Human Organization 63:472-486.

Berlin, B., E. A. Berlin, E. J. C. F. Ugalde, L. G. Barrios, D. Puett, R. Nash, and A. M. GonzálezEspinoza. 1999. The Maya-ICBG: Drug Discovery, Medical Ethnobiology, and Alternative Forms of Economic Development in the Highland Maya Region of Chiapas, Mexico. Pharmaceutical Biology 37:127-144.

Bjorkan, M., M. Qvenild. 2010. The Biodiversity Discourse: Categorisation of Indigenous People in a Mexican Bio-prospecting Case. Human Ecology 38:193-204.

Convention on Biological Diversity. About the Nagoya Protocol [web page]. Available at: https:// www.cbd.int/abs/about/default.shtml. Accessed on January 8, 2018.

Garcia, J. 2007. Fighting Biopiracy: The Legislative Protection of Traditional Knowledge. Berkeley La Raza Law Journal 18:5-28.

Hardison, P. 2000. ICBG-Maya: A Case Study in Prior Informed Consent. The Monthly Bulletin of the Canadian Indigenous Caucus on the Convention on Biological Diversity. Available at: http:// trade.ec.europa.eu/doclib/docs/2005/april/ tradoc_122179.pdf. Accessed on January 8, 2018.

Herreid, C. F. 2005. The interrupted case method. Journal of College Science Teaching 35:4-5.
International Society of Ethnobiology. History of the Code of Ethics [web page]. Available at: http:// www.ethnobiology.net/what-we-do/coreprograms/ise-ethics-program/code-of-ethics/brief -history/. Accessed on January 8, 2018.

International Society of Ethnobiology. 2008. ISE Code of Ethics [web page]. Available at: http:// www.ethnobiology.net/wp-content/uploads/ISECOE_Eng_rev_24Nov08.pdf. Accessed on January 8, 2018.

Nath, J. L. 2005. The Roles of Case Studies in the Educational Field. International Journal of Case Method Research and Application XVII 3:396-400.

Nigh, R. 2002. Maya Medicine in the Biological Gaze: Bioprospecting Research as Herbal Fetishism. Current Antbropology 43:451-477.

Oviedo, A. C., P. R. Field, and D. J. Shebitz. 2018. Indigenous Knowledge and the Search for Medicine: Controversy in Chiapas. National Center for Case Study Teaching in Science, University at Buffalo, State University of New York, Buffalo, NY. Available at: http:/ libweb.lib.buffalo.edu/ cs $/$ collection/detail.asp?id=960\&case_id $=960$. Accessed on January 8, 2018.

RAFI (Rural Advancement Fund International). 2000. Stop Biopiracy in Mexico! [web page]. Available at: http://www.gmwatch.org/en/news/ archive/2000/8836-rafi-stop-biopiracy-in-mexico24102000. Accessed on January 8, 2018.

Rosenthal, J. 1997. Integrating Drug Discovery, Biodiversity Conservation, and Economic Development: Early Lessons from the International Cooperative Biodiversity Groups. In Biodiversity and Human Health, edited by F. Grifo and J. Rosenthal, pp. 281-201. Island Press, Washington, DC.

Rosenthal, J. 2006. Politics, Culture, and Governance in the Development of Prior Informed Consent in Indigenous Communities. Current Anthropology 47:119-142.

Soto, J. C. 2000. Pukuj: Biopirateria en Chiapas. San Cristobal de Las Casas, Chiapas, Mexico. 